\title{
NIETZSCHE E A QUESTÃO DOS SENTIDOS DO EU: POTÊNCIA E IMPOTÊNCIA NOS PROCESSOS INTERPRETATIVOS
}

\section{Nietzsche and the problem of the menings of the self: power and weakness in processes of interpretation}

Daniel B. Portugal ${ }^{1}$

RESUMO: Este trabalho analisa duas formas antagônicas de produção de sentido, tais como elas aparecem no pensamento "maduro" de Nietzsche: uma proveniente da apropriação de algo pela vontade, outra resultado da incapacidade da vontade de se apropriar de algo. Procurando compreender como essas duas formas de produção de sentido atuam na construção de um "eu", o artigo investiga algumas relações entre os conceitos de vontade, sentido e sujeito na obra do filósofo. Por fim, como uma ilustração da discussão conceitual, apresento alguns resultados de um trabalho recente no qual mapeio formas negativas de articulação de sentidos em diferentes teorias da psique.

Palavras-chaves: Sentido. Vontade. Sujeito. Nietzsche.

ABSTRACT: This paper analyzes two antagonistic forms of meaning-making as they appear in Nietzsche's "mature" philosophy: the first one is the result of the appropriation of something by the will, the other derives from the inability of the will to appropriate something. Seeking to understand how these two forms of meaning-making act in the construction of the ego, the article investigates some relations between the concepts of will, meaning and subject in the work of Nietzsche. Finally, as an illustration of the conceptual discussion, I present some results of a recent work in which I map negative forms meaning-making in different theories of the psyche.

Keywords: Meaning. Will. Subject. Nietzsche.

${ }^{1}$ Professor adjunto da ESDI/UERJ. Doutor em Comunicação e Cultura pela UFRJ. 


\section{INTRODUÇÃO}

A questão do sentido é um dos temas centrais da filosofia de Nietzsche, especialmente o sentido como organizador das relações que o sujeito estabelece consigo e com suas vivências. Como se sabe, na tradição metafísica, o que dá sentido a essas relações é o plano do divino perfeito, eterno e imutável. A constatação nietzschiana de que Deus está morto, portanto, recoloca de imediato, e de maneira urgente, a questão do sentido para a vida humana. A ilustração mais emblemática desse problema aparece no prólogo de Assim falou Zaratustra, na cena em que o equilibrista cai semi-morto aos pés do protagonista, acreditando-se destinado ao inferno. Zaratustra então lhe diz: "nada do que falas existe: não existe demônio nem inferno. Tua alma morrerá ainda antes que teu corpo: nada temas, portanto!". Ao que o equilibrista responde: "Se falas a verdade, então nada perco, ao perder a vida. Não sou muito mais que um animal que ensinaram a dançar, com golpes de bastão e pequenos nacos de comida". Mas Zaratustra não aceita tal conclusão. De maneira nenhuma, afirma, "fizeste do perigo teu ofício, não há o que desprezar nisso" (NIETZSCHE, 2011, p. 20 [Z, prólogo, 6]). O equilibrista não consegue encontrar sentido para sua vida sem recorrer a Deus e ao demônio, mas Zaratustra lhe indica uma outra possibilidade de sentido, calcada no risco, uma vez que não conta mais com nenhuma garantia.

Contudo, as indicações de Zaratustra não são recebidas com muito entusiasmo pelo povo, que não quer de modo algum o risco, mas novas garantias. Ou seja, a maioria das pessoas procura preservar, mesmo que de maneira debilitada, o mesmo tipo de sentido que a tradição metafísica lhes garantia. Outros, porém, frente à derrocada de Deus, abrem-se para este outro tipo de sentido do qual Zaratustra é o porta-voz. Temos, portanto, dois tipos diferentes de sentido, que organizam diferentes relações do sujeito consigo e com suas vivências. Meu principal objetivo neste trabalho é estudar as peculiaridades desses dois tipos de sentido no pensamento "maduro" de Nietzsche (minhas principais referências serão obras publicadas após o Zaratustra: Além do bem e do mal, Genealogia da moral e Crepúsculo dos ídolos). Em seguida, como uma ilustração da discussão conceitual, apresentarei alguns resultados de um trabalho recente no qual mapeio os sentidos oferecidos por certas teorias da psique, as quais, indicando caminhos para o "bem do sujeito", procuram reconstruir as garantias metafísicas com novas roupagens.

\section{SENTIDO, SUJEITO E VONTADE}

A ideia de "sentido", muitas vezes, remete a um fim determinado. Por exemplo: se estou assistindo a um jogo de xadrez e alguém faz uma jogada que me parece estranha, posso perguntar: 
qual é o sentido dessa jogada? Com isso, quero entender a relação da jogada com um fim que considero já dado pelo próprio jogo. Se acredito que a jogada não leva ao fim pressuposto, diria que ela não faz sentido, ou seja, que a jogada foi um erro, uma vez que não seria possível querer outra coisa que não ganhar o jogo segundo os parâmetros do próprio jogo. Lidamos com o "sentido" de outras forma se atentamos para o tipo de ação conjunta que é mediada pelas regras do xadrez, mas que não está subordinada a elas. O jogo de xadrez, nesse caso, configura-se como um campo de disputa no qual não apenas um adversário enfrenta o outro, mas no qual os dois se submetem a certas forças cristalizadas na própria tradição do jogo de xadrez e na organização desta disputa específica, agindo também, ao mesmo tempo, sobre os espectadores. No primeiro caso (sentido 1), "sentido" é algo que já está dado, e que se recebe; no segundo caso (sentido 2), "sentido" é algo que se dá na ação, e que efetiva uma apropriação. Pensando na primeira acepção do termo (sentido 1), Nietzsche (2006, p. 12 [CI, Máximas e flechas, 18]) escreve: “Quem não sabe pôr sua vontade nas coisas lhes põe ao menos um sentido: isto é, acredita que nelas já se encontra uma vontade".

O sentido, portanto, é aqui pensado como uma incapacidade da vontade, ou seja, resultado de uma impotência. Quem não sabe pôr sua vontade nas coisas lhes põe ao menos um sentido. Mas quem põe sua vontade nas coisas também lhe confere um sentido, só que é outro tipo de sentido, o que estou chamado de sentido 2. Neste último caso, o sentido é uma forma de se apoderar de algo, e não de justificar a existência de uma coisa da qual não se consegue apoderar. ${ }^{2}$ Tal sentido 2 é evidenciado no seguinte trecho da Genealogia da moral: “[...] todo subjugar e assenhorar-se é uma nova interpretação, um ajuste, no qual o 'sentido' e a 'finalidade' anteriores são necessariamente obscurecidos e obliterados" (NIETZSCHE, 2009, p. 60-61 [GM, II, 12]). Tal formulação é parte da crítica de Nietzsche à noção de que a finalidade de uma coisa seria o fundamento de sua gênese. Vejamos o caso do castigo, que o filósofo discute na dissertação citada: suponhamos como certo que a punição por um crime sirva para desencorajar outros de cometerem o mesmo crime; isso não significa que a vontade de desencorajar potenciais criminosos tenha produzido pela primeira vez um ato reconhecido como punição, ou seja, uma ação promotora de sofrimento como forma de retribuir outra ação promotora de sofrimento. O ponto é que "algo existente, que de algum modo chegou a se realizar, é sempre reinterpretado para novos fins, requisitado de maneira nova, transformado e redirecionado para uma nova utilidade, por um poder que lhe é superior [...]” (Ibidem). Portanto, o atual sentido de algo não é a razão de sua constituição. Quem coloca a função momêntanea de algo como base de sua gênese faz o mesmo que um biólogo que acredita que o olho foi feito para ver e a mão para pegar. Nietzsche, ao contrário, percebe que

\footnotetext{
${ }^{2}$ O sentido 1 não deixa de ser também um tipo imaginário de apropriação da coisa, mas certamente diferente do primeiro tipo, como veremos adiante.
} 
o sentido de uma coisa, que engloba sua finalidade ou função, determina-se pela inserção de tal coisa em uma rede. Poderíamos dizer que a coisa é a todo momento "pescada" por uma vontade que a define de novas maneiras.

Nessas breves considerações sobre "sentido", foi possível notar, então, que as duas maneiras de dar sentido estudadas se definem pela sua relação com uma vontade. No primeiro caso, o sentido provém de uma incapacidade da vontade de se apoderar de algo, no segundo, ao contrário, justamente do apoderamento de algo por uma vontade.

Mas é preciso destacar que a "vontade" que está em jogo aqui não é a vontade da qual temos consciência, que seria, em termos schopenhauerianos, uma representação da vontade, ou a vontade empírica, "[...] acompanhada de conhecimento segundo motivos [...]" (ver: SCHOPENHAUER, 2005, p. 170 [MVR, \22]), mas sim a vontade pensada como força - não como uma espécie específica de força, mas como aquilo que permite compreender o que é uma força. Como coloca Schopenhauer: "[...] intento pensar cada força na natureza como vontade" (Ibidem). A ideia de força é útil porque uma força se caracteriza como tal justamente pela sua possibilidade de se apoderar de algo para além de si mesma. Parece-me ser este um ponto central daquilo que Nietzsche pretende indicar com sua expressão vontade de poder.

O principal aqui é o fato de que não se trata de uma vontade do sujeito, nem da força do sujeito, pois uma das tarefas desse vocabulário é justamente deslocar a noção de sujeito, ressituando-o não como causa daquilo que acontece, mas como algo que se acrescenta aos acontecimentos, emprestando-lhes, justamente, um sentido.

A vontade consciente que aparece para nós, normalmente já vinculada a uma narrativa causal, ou seja, a motivos que nos levariam a querer aquilo que queremos, é já o resultado de um processo que dá sentido a certas vontades que atuam em nós. Obviamente, isso não é simples de conceber ou mesmo de falar, em parte porque a própria gramática, como diz Nietzsche, já orienta nossas interpretações de diversas maneiras e, nesse caso específico, de maneira muito clara: requerendo um sujeito para os verbos, como se a ação dependesse de um sujeito. ${ }^{3}$ Nesse caso, temos até certa vantagem com o português que ao menos admite alguns verbos impessoais, como quando dizemos “chove”. No alemão, é preciso acrescentar um elemento que funciona como um paradoxal sujeito impessoal, algo como "isso" chove. Daí justamente que Nietzsche (e depois Freud) vão utilizar esse elemento, o Es, para indicar o caráter impessoal daquilo que fazemos e falamos, ou seja, deslocar o sujeito de seu papel de senhor e causa de suas falas e atos. E o exemplo

\footnotetext{
3 "Pois antigamente se acreditava na 'alma', assim como se acreditava na gramática e no sujeito gramatical: dizia-se que 'eu’ é condição, 'penso' é predicado e condicionado - pensar é uma atividade, para a qual um sujeito tem que ser pensado como causa” (NIETZSCHE, 2009, p. 53 [ABM, 54]).
} 
do "chove" realmente nos ajuda aqui, se pensarmos no exemplo que Nietzsche (2009, p. 33 [GM, I, 13]) oferece na Genealogia da moral para explicar o lugar do sujeito:

[...] pois assim como o povo distingue o corisco do clarão, tomando este como ação, operação de um sujeito de nome corisco, do mesmo modo a moral do povo discrimina entre a força e as expressões da força, como se por trás do forte houvesse um substrato indiferente que fosse livre para expressar ou não a força. Mas não existe um tal substrato; não existe 'ser' por trás do fazer, do atuar, do devir; o 'agente' é uma ficção acrescentada à ação - a ação é tudo.

Em resumo: todo verbo é impessoal. O sujeito não é aquele que realiza a ação ou que the dá sentido, mas é, ele mesmo, conformado pela "captura" da ação por um campo de sentido determinado por uma vontade. Tal vontade não é uma substância, mas indica movimentos de domínio ou de declínio, em relação aos quais somente os entes ganham um sentido definido. $\mathrm{O}$ que podemos acessar por meio dos entes tal como eles aparecem para nós - incluindo a aparição de nosso próprio eu como objeto para nós - não é, portanto, uma suposta essência por trás deles, mas um modo de apropriação que os revela de uma forma ou de outra. Tal modo de apropriação é também um tipo de interpretação que faz o movimentos volitivos, em si mesmos indiferentes acaso, como os chama Nietzsche -, aparecerem como sentido (ver: NIETZSCHE, 2006, p. 42 [CI, Os quatro grandes erros, 4]).

A partir do que foi dito, podemos tentar esquematizar a relação entre sentido, sujeito e vontade tal como ela aparece na filosofia "madura" de Nietzsche. É possível perceber que tal relação é completamente diferente daquela que estabelece a tradição metafísica que se incorporou no senso comum (e em nossa língua, como indicado acima). O sujeito não está na base do querer e do pensar, da vontade e do sentido; ao contrário, o sujeito é uma fição, parte de certo campo de sentido que se deriva da expansão ou da supressão de vontades. E, embora não haja fixidez na base do sentido (pois as "vontades" em questão não são novos tipos de sujeito do movimento, elas indicam apenas o próprio ímpeto de superação), certas maneiras de dar sentido podem se fixar por longos tempos, dominar outros modos de dar sentido, até serem sobrepujadas por outras ou suprimirem-se a sim mesmas pelo próprio movimento expansivo das vontades que lhes sustentam na existência.

O sentido aparece então como a "ponte" entre vontade e sujeito, ou seja, aquilo que pode dar unidade, identidade, a algo que, em si, não possui ordem - que é acaso. Seria só a partir do recorte operado por certas maneiras de dar sentido, ou seja, de certas interpretações e valorações, que chegaríamos a articular essas entidades fundamentais em nossas vivências que são sujeito e objeto. É nesse sentido que o mundo ordenado que aparece para nós, incluindo a identidade que assumimos no mundo - o eu - se configuram como uma ficção: 
Por que não poderia o mundo que nos concerne - ser uma ficção? E a quem faz a pergunta: 'mas ficção não requer um autor?' - não se poderia replicar: Por quê? Esse 'requer' não pertenceria também à ficção? Não é permitido usar de alguma ironia em relação ao sujeito, como em relação ao predicado e objeto? (NIETZSCHE, 2005, p. 39 [ABM, 34]).

Essa noção de ficção, relacionada, como está, à colocação de vontades impessoais na base da produção de sentido, elimina de imediato tanto a possibilidade de um sentido "neutro" quando a de um sentido que seja controlado e produzido ex nibilo por um sujeito. As maneiras de dar sentido sempre respondem a certas vontades, são expressões das vontades, dos movimentos de apoderamento.

É importante destacar que as próprias regras que legitimam certo tipo de conhecimento como verdadeiro - sejam as regras da palavra revelada, da lógica ou do método científico precisam ser instituídas como tais, e que tal instituição é já uma forma de apropriação do pensamento por certa vontade que se expressa nessas regras mesmas. Ao utilizarmos a lógica ou o método científico, portanto, continuamos nos relacionando com um tipo específico de ficção, apenas com regras mais claras para a definição do que pode ser tomado por verdade.

Assim, quando imaginamos fugir de nossos "preconceitos" para buscar um sentido supostamente "objetivo", uma suposta verdade do que estaria ocorrendo conosco (por exemplo, deixando de entender nossa tristeza de uma maneira difusa para encontrar a verdade sobre ela recorrendo ao diagnóstico de um psiquiatra), aí estamos também aderindo a um sentido parcial como sempre fazemos. A pergunta a ser colocada não pode ser mais a da adequação de certo significado ao que seriam os fatos em si mesmos ou à verdade do que somos. Uma vez que estamos lidando sempre com ficções, as únicas questões a ser colocadas são: 1. A da relação de certos significados com os movimentos volitivos que os engendram. 2. As formas de delimitação do eu e dos objetos nesses campos de sentido.

Voltamos, assim, ao tema do início deste tópico, o das duas acepções do termo "sentido", que se diferenciam entre si por estabelecerem relações diferentes com a vontade: de um lado, um sentido que é efeito da incapacidade da vontade de se apropriar de algo, de outro, um sentido resultante da apropriação de algo pela vontade. Uma ressalva a ser feita diz respeito ao estatuto do sentido 1, pois, apesar de derivar-se de uma incapacidade de agir, é preciso notar que a atribuição de sentido mesmo se constitui como uma forma de agir imaginariamente sobre um objeto do qual não se consegue apropriar - que faz sofrer. O ponto é que essa vingança imaginária, fruto da impotência, é um modo de produção de sentido completamente diferente da criação advinda da potência: o primeiro parte da sensação de impotência para designar algo como mau - e apenas em função de tal mal, como uma negação dele, algum sentido positivo pode ser erigido; o segundo modo 
de produção de sentido, ao contrário, parte da experiência de dominação, da força sendo exercida, e essa experiência mesma é afirmada e se cristaliza como ideal positivo - só na comparação com ele, sentidos negativos como os de fraqueza, infelicidade, incapacidade etc. emergem (ver: NIETZSCHE, 2009 [GM, I, 5-14]). O primeiro, portanto, é negativo, o segundo, afirmativo. Esse é um tópico que Nietzsche desenvolve com bastante detalhe na Genealogia da moral. Mas, para os propósitos deste trabalho, acredito que essa apresentação é suficiente, se complementada com um exemplo, que ilustra o tipo de olhar que podemos lançar para sentidos específicos se tomarmos como base o arcabouço teórico aqui delineado.

\section{O CASO DO LIVRE-ARBÍTRIO}

Vejamos como poderíamos proceder na análise de construções semânticas particulares e tomemos como ponto de partida a questão da liberdade da vontade. Somos livres? De imediato, sabemos que não é possível responder de maneira absoluta com um sim ou um não, mas temos que compreender os campos de sentido que permitem colocar esta questão de uma maneira ou de outra. Quais seriam essas formas de apropriação do conceito de livre-arbítrio, a partir das quais, somente, podemos compreender seus sentidos?

Podemos observar duas formas gerais de adesão à noção de liberdade da vontade, uma afirmativa outra negativa, tal como delineado anteriormente. Investigando o primeiro caso, Nietzsche percebe que o conceito de livre-arbítrio parece provir da sensação de superioridade daquele que manda: "O que é chamado livre-arbítrio é, essencialmente, o afeto de superioridade em relação àquele que tem que obedecer” (NIETZSCHE, 2005, p. 23 [ABM, 19]). E isso pode ser pensado tanto em termos intrasubjetivos, como faz o filósofo no aforismo citado, quanto intersubjetivos. Ou seja, "aquele que tem que obedecer" pode ser uma parte de nós que consideramos "não eu" porque nos identificamos com a outra parte, que manda, ou pode ser outro indivíduo, que percebemos como distantes de nós mesmos por estar ele compelido a obedecer.

Já no segundo caso, na forma negativa de construção de sentido, proveniente da impotência, fisiologicamente degenerada de adesão a tal ideal, o conceito de liberdade figura como a chave que permite transformar a impotência em um mérito - ele converte o "não posso" em "não quero".

[...] graças ao falseamento e à mentira para si mesmo, próprios da impotência, [a prudência de não fazer o que não se tem forças para fazer] tomou a roupagem da virtude que cala, renuncia, espera, como se a fraqueza mesma dos fracos [...] fosse um empreendimento voluntário, [...] um mérito (NIETZSCHE, 2009, p. 34 [GM, I, 13]). 
A liberdade da vontade é, nesse caso, uma criação que permite valorar como moralmente boa a própria impotência. Ela oferece, ainda, a possibilidade de uma vingança imaginária sobre a força, na medida em que a própria força é caracterizada como uma escolha de um sujeito, e como uma escolha moralmente má.

A invenção do outro mau é indissociável de uma explicação para o sofrimento que nos ajuda também a darmos sentido ao que somos: vítimas injustiçadas das ações indevidas desses outros maus. Mas, particularmente interessante para nós, é a possibilidade de substituirmos o "outro mau" por um mal dentro de nós - substituição tornada possível por noções como a de "culpa", que Nietzsche enxerga como a grande criação dos sacerdotes ascéticos.

A noção de culpa permite ao impotente sofredor procurar a explicação de seu sofrimento, fracasso, angústia etc. em algo que ele mesmo teria feito e que lhe tornaria responsável por seu próprio sofrimento: “ávido de motivos [...], o homem [...] recebe do seu mago, o sacerdote ascético, a primeira indicação sobre a 'causa' do seu sofrer: ele deve buscá-la em si mesmo, em uma culpa, um pedaço de passado, ele deve entender seu sofrimento mesmo como uma punição..." (NIETZSCHE, 2009, p. 122 [GM, III, 20]). Também a forma negativa de utilização do conceito de livre-arbítrio, portanto, pode transitar entre os planos intersubjetivo e intrasubjetivo.

\section{AS BESTAS DENTRO DE NÓS}

A escolha do conceito de livre-arbítrio para a breve análise do tópico anterior não se deu por mero acaso. A delimitação de uma noção afirmativa de liberdade é cara a Nietzsche, e nos permite compreender a seguinte lição de Zaratustra: "livre de quê? Que importa isso a Zaratustra! Mas teus olhos devem claramente me dizer: livre para quê??" (NIETZSCHE, 2011, p. 61 [Z, I, Do caminho do criador]).

A oposição entre "liberdade de quê?" e "liberdade para quê?" sintetiza bem a diferença entre os sentidos negativo e afirmativo de liberdade pois, no primeiro caso, vemos que o elemento central é o mau em oposição ao qual a liberdade se define, enquanto, no segundo, o elemento central é a própria liberdade, que define um horizonte específico de possibilidades práticas.

Acredito, então, que as partes anteriores delinearam de maneira suficiente um tipo de trabalho interpretativo - bermenêutico, gostaria de chamá-lo -, derivado da filosofia de Nietzsche, que permite alcançar uma compreensão das disputas de vontades na base da construção de certos campos de sentido. No que segue, apresentarei rapidamente alguns resultados de um trabalho 
recente no qual parto de tal hermenêutica para analisar diferentes teorias da psique - me refiro ao meu livro As bestas dentro de nós (PORTUGAL, 2019).

Nietzsche se debruçou frequentemente sobre teorias psicológicas de base platônico-cristã e identificou nelas um trabalho essencialmente negativo de construção de identidade. O que guiou meus esforços na pesquisa que agora descrevo foi a percepção de que teorias “modernas", mesmo algumas muito diversas tematicamente das teorias da psique de bases platônico-cristãs, mantinham a mesma forma geral de atribuição de sentido.

Assim, desenvolvi um trabalho de mapeamento do que podemos caracterizar como maneiras negativas de dar sentido ao eu. Tais campos de sentido costumam se construir sobre uma divisão moral da subjetividade: de um lado uma parte má, que nos dominaria indevidamente - uma besta dentro de nós -; de outro, um "eu” essencialmente bom porque definido negativamente em função da parte má. A parte má é, portanto, sempre a mais fundamental, e é por isso que intitulei o livro $A s$ bestas dentro de nós.

Em um mapeamento preliminar, identifiquei três bestas principais, ou seja, três campos semânticos principais que, nos últimos séculos, permitiram identificar em nós uma parte má e conceber, em oposição a ela, um "verdadeiro eu" a ser libertado. Emprestei a cada uma dessas bestas o nome de um animal ou monstro representativo, por acreditar que o uso de metáforas ajudaria a evitar uma possível leitura realista da obra. As bestas, enfim, são as seguintes:

Lobo. É a besta ligada a nossos desejos, apetites, paixões, impulsos, sensualidade, cobiça, prazeres etc., na medida em que são encarados como algo mau que emana da matéria, do corpo, da carne (no sentido cristão) e/ou de um apego egoísta à individualidade. Como ocorre com as demais bestas, o lobo é percebido como aquilo que nos afasta de um eu que consideramos mais real ou verdadeiro e associamos ao bem. No caso do lobo, esse "verdadeiro eu" que se corrompe ao entrar em contato com os caninos afiados da besta está ligado à razão, à benevolência ou à conexão com algum tipo de transcendência.

Dragão. É a besta ligada às regras sociais interiorizadas, à vontade social que atua dentro de nós, ou a uma vontade maquinal, inumana em suas regras e racionalidades, na medida em que imaginamos que ela nos reprime, oprime ou aliena. O "verdadeiro eu" que se supõe arder sob o fogo do dragão é associado à espontaneidade, naturalidade, autenticidade, humanidade e, na maioria das vezes, a algum tipo de conexão, seja material ou espiritual, com a natureza percebida como um todo imanente.

Cão. É a besta relacionada ao sofrimento (ou à aguda sensação de inadequação a parâmetros interpretativos/valorativos relacionados à felicidade e normalidade) na medida em que ele é encarado como doença mental ou algum tipo de disfunção, entendida em sentido estrito como um 
problema de funcionamento. Pode ser a disfuncionalidade do corpo ou da mente, embora esta última seja costumeiramente percebida, no imaginário bestializador do cão, como um subproduto do corpo. O "verdadeiro eu" que o cão ataca com suas garras está normalmente relacionado à saúde, ao prazer e à normalidade.

Embora haja diversas peculiaridades nos campos de sentido que definem cada besta (ver partes I, II e III do livro citado), o que quero destacar é o trabalho essencialmente negativo de contrução de sentido para o eu que tais campos operam. Não é por acaso que todos eles se definem por uma besta, ou seja, por uma parte má concebida dentro de nós. As bestas oferecem uma causa imaginária para as tensões envolvidas em qualquer delimitação de um eu organizado, e revelam uma incapacidade de lidar com essas tensões. Os campos semânticos bestializadores têm como eixo a busca por uma uma causa que explique essas tensões e por valores universais já dados que estariam escondidos por trás das bestas. Eles oferecem, enfim, conforto e justificam a inação.

As maneiras afirmativas de dar sentido ao eu, diferentemente das bestializadoras, não negam a constante disputa inteiror - justamente a valorização dessa disputa é indício de potência, de um sentir prazer no exercício da força. Daí a noção de Nietzsche (2006, p. 35 [CI, Moral como antinatureza, 3]), de que, de um ponto de vista afirmador, tendemos a valorizar nossos inimigos, incluindo o "inimigo interior", e a reconhecer seu valor, como elemento indispensável da luta que somos. Nessa perspectiva, o inimigo interior não figura como uma besta, como um "inimigo mau", mas simplesmente uma parte de nós em tensão com outras partes com as quais, no momento, nos identificamos. Nesse sentido, o eu é percebido como o resultado provisório de um processo fluido que envolve necessariamente disputas diversas, e não como algo já dado, bom e completo. De tal maneira, Nietzsche afirma a experiência de vida em suas multiplicidades e contradições. Interessa ao filósofo, como escreve Edmilson Paschoal (2014, p. 28), "apontar modos de se colocar diante da vida em toda a sua complexidade, sem que, para isso, seja necessário negar algum de seus multifacetados aspectos ou buscar meios para minimizar a tensão que é própria à existência".

\section{CONSIDERAÇÕES FINAIS}

Comecei este trabalho fazendo referência a uma cena de Assim falou Zaratustra que me parecia evocar a urgência da questão do sentido do que somos após a constatação da morte de Deus. A breve fala de Zaratustra indicava a possibilidade de uma forma afirmativa de construção de sentido, mas a recepção de sua fala pela maioria das pessoas sugeria que a vontade dominante era a de preservar, ainda que de maneira debilitada, o mesmo tipo de sentido que a tradição metafísica lhes garantia. Em seguida, analisei com cuidado, a dupla filiação do "sentido" na filosofia 
de Nietzsche - de um lado, o sentido como efeito da incapacidade de apropriação de algo pela vontade, de outro, o sentido como resultante do apoderamente de algo pela vontade. Tal análise tornou possível delinear um caminho interpretativo, ou, como preferi chamá-lo, uma hermenêutica, que permitiria alcançar uma compreensão das disputas de vontades na base da construção de certos campos de sentido. Foi recorrendo a tal caminho interpretativo que realizei, em outro trabalho (meu livro As bestas dentro de nós), um mapeamento de diversas teorias da psique. Descrevi então os resultados de tal trabalho, apontando que boa parte das teorias modernas da psique, ainda que recusem tematicamente as soluções metafísicas, são, em última análise, apenas novos produtos da mesma oficina de ideiais. Assim, percebemos que, no senso comum de nossa cultura, continuam hegemônicas as formas negativas de construção de sentido para o eu. Tal constatação apenas revela a atualidade do pensamento de Nietzsche e a relevância de suas reflexões sobre as possibilidades afirmativas de produção de sentido.

\section{REFERÊNCIAS}

NIETZSCHE, Friedrich. Assim falou Zaratustra. Trad. P. C. de Souza. São Paulo: Companhia das Letras, 2011.

. Genealogia da moral. Trad. P. C. de Souza. São Paulo: Companhia das Letras, 2009.

. Crepúsculo dos ídolos. Trad. P. C. de Souza. São Paulo: Companhia das Letras, 2006.

. Além do bem e do mal. Trad. P. C. de Souza. São Paulo: Companhia das Letras, 2005.

PASCHOAL, Edmilson. Nietzsche e o ressentimento. São Paulo: Humanitas, 2014, p. 28.

PORTUGAL, Daniel B. As bestas dentro de nós. Rio de Janeiro: Áspide, 2019.

SCHOPENHAUER, Arthur. O mundo como vontade e como representação. Trad. J. Barboza.

São Paulo: UNESP, 2005. 